\title{
The Drawing of the Archaeological City of Pompeii
}

\author{
Luigi Corniello
}

\begin{abstract}
The research is focused on the drawings that stimulate direct analysis of the architecture and the urban environment. The reading for the critical and architectural knowledge of the role of the drawing, of the static and visual function, the relationship between the internal and external space and dimensional and aesthetical relationships on to the ancient city of Pompeii. A knowledge based on the measurement of the heritage that extends the traditional notions of geometry and measuring, and allows us a multidimensional representation, in which each component, material and immaterial, returns the urban landscape as a dynamic entity in constant evolution. In the application of this method consist of the Pompeii archaeological territory, on which knowledge consisted of the reading given to the understanding of all aspects that contribute to determining the form, not only as the outward appearance, but also as a carrier of related values the history, the culture and the traditions which over the centuries have stamped their marks to the natural environment. Know an area it means to browse the history of the urban fabric, acquiring social structures, drawing the architectural presence of the present and the past, capture the value of human heritage, including the urban and monumental image of a place, its measurable identity. The measure, therefore, is the basis of knowledge and every representation of reality and documentary tracks.
\end{abstract}

Index Terms - Architecture, Drawing, Pompeii, Representation

\section{INTRODUCTION}

The research is focused on the built environment documents the ancient city of Pompeii, pursuing the detection methods performed in the nineteenth century and the geometric analysis of the domus. The methods adopted by the surveyors, architects, draftsmen, landscape artists, testified, regardless of the techniques and the exact match to the actual situation, the progressive cultural engagement in the representation of the works examined.

The scientific contribution and technical merit of the drawings of Italian and international artists from the nineteenth century to today testified research in support of further studies to remember how some architects of the Enlightenment age from surveys and graphics of the Vesuvian they drew antiquities and culture the creative activities of villas, theaters, public buildings and street furniture. They are to highlight the drawings and the surveys carried out in order to reconstruct, for analyzing building process of the Pompeian factories.

They are graphics that stimulate a direct the architecture and the urban analysis: analysis for the historical and critical knowledge of the architectural role of the static and the visual

Manuscript received April 17, 2016.

Luigi Corniello, Second University of Naples, Department of Architecture and Industrial Design Aversa, Caserta, Italy function, the relationship between the internal and external space and dimensional and aesthetical relations. We can also say that the Vesuvian archaeological events have considerably boosted to synergies from different disciplines; historiography of the ancient world that was developed by interpolating the knowledge of the archaeologist and photographer, the detector and the architect, the draftsman and landscape painter.

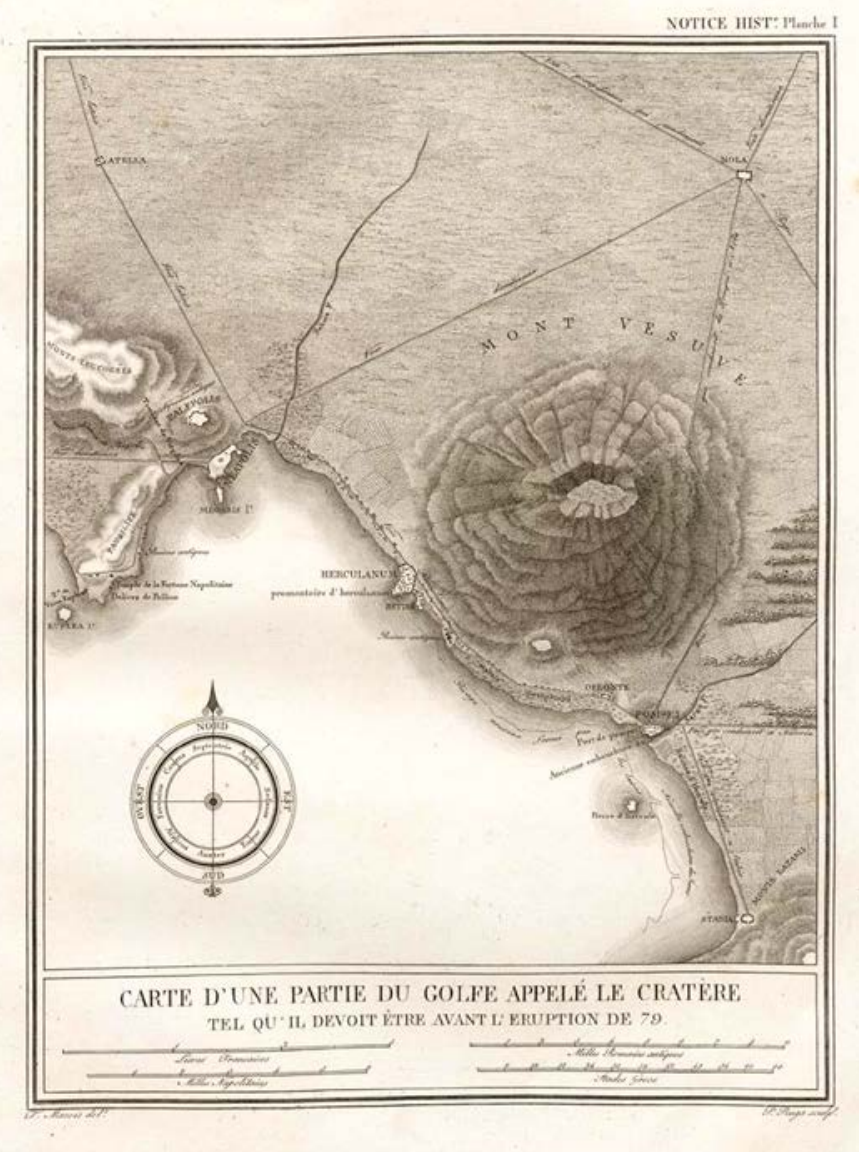

Fig. 1. Charles Francois Mazois, Les ruines de Pompéi, Paris, 1824, V. I Planche I

As regards the survey are to consider the recent acquisition operations through the 3D digital recording, laser scanners or photogrammetric. The latest 3D laser scanner technologies integrate the laser sensor to the photographic so as to acquire from each point of Cartesian and photographic data views that are unique synthesis and representation in the point cloud photo-realistic reality. The integration technology could be completed with the accurate calculation of GPS antennas: the Cartesians data will be referred to as absolute geocentric systems and are no longer on to the field architectural or urban. 


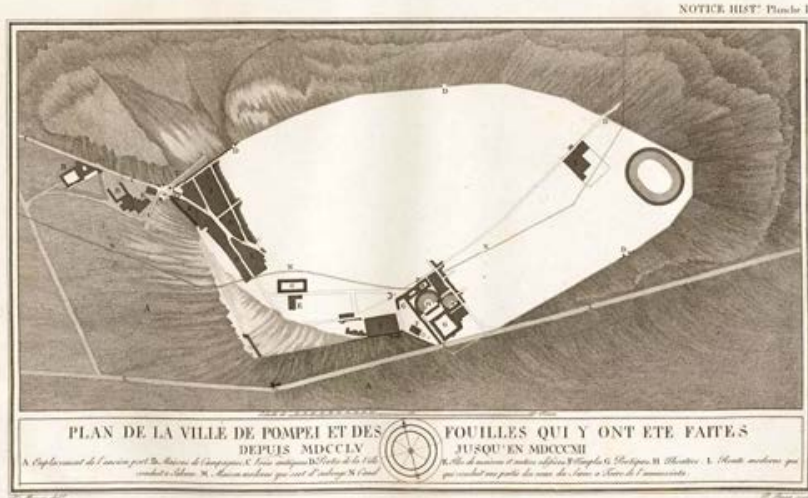

Fig. 2. Charles Francois Mazois, Les ruines de Pompéi, Paris, 1824, V. I Planche II

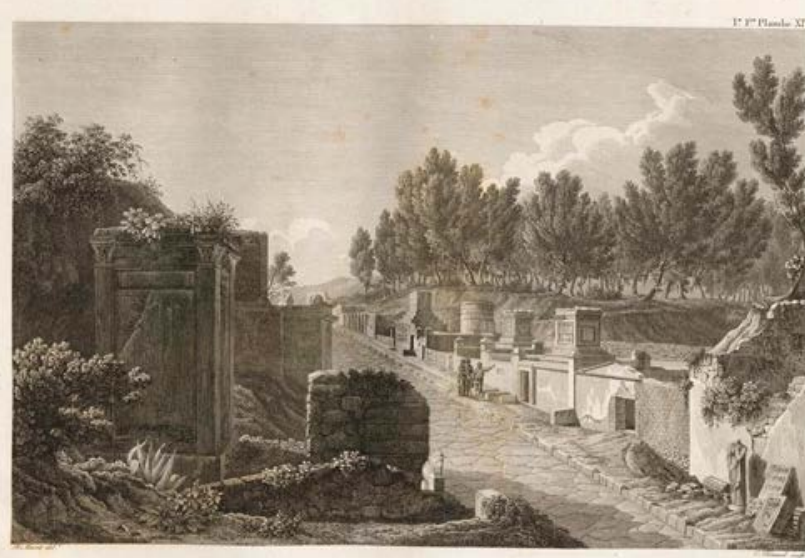

Fig. 3. Charles Francois Mazois, Les ruines de Pompéi, Paris, 1824, V. I Planche XIV

\section{The ARChaEOlOgicAl DraWING In POMPEII}

One of the first of Pompeii graphics of the archaeological documents is a sketch drawn by Francois Latapie. This document constitutes the most immediate description that yes knows the first excavations of Pompeii, in addition to the testimony of a French traveler who along the archaeological area annotates aspects and features. Latapie refers to monuments, then exhumed, among which Porta Ercolano, the Temple of Iside, the House of the Chirurgo and the so-called Villa di Cicerone, take a few drawings to complex urban and textual observations of a technical nature documentary on the conduct of the excavations, on the plantations that covered the urban area and the stratification of the eruptive material.

For the documentation and the protection of urban planning Vesuvian area is remarkable the activity of the archaeologist Giuseppe Fiorelli under the direction of which was resumed, with new operational guidelines, the excavations at Pompeii in 1861 and in 1869 at Herculaneum. The archaeologist, together with the conduct of the meeting, began publishing a newspaper of Pompeii to describe, in detail, the work that you were carrying. The biggest innovation introduced was the excavation of the executed method in the middle of systematic excavation interventions progressing vertically from the top downwards. Of great interest is the floor plan of all excavations obtained with geodetic survey and the table of triangulation carried on Pompeian territory as part of the perimeter of the walls and the design of the demarcated structures of some domus and public buildings in the various insulae bounded by the axes roads. Each monument are also shown, by means of alphabetical letters, the intended use and found furniture.

During the leadership of Fiorelli was acquired and developed between the experts heard a critical awareness on the direct analysis problems of ancient works in the middle of their precise graphic recording and development of drawing with the criterion of systematization of the layers of the reported bodies to the light. One entered so in a new operational phase for the knowledge of Pompeian monuments.

In the graphic documentation of Pompeian monuments is considerable the relief of the Paccard, executed around 1845, on the Basilica of Pompeii. It is a painstaking relief of the plant and of the residues of elevation walls with average height of 4.50 meters and a ionic capital of the facade on the hole: it is a scale drawing with dimensions. Between the writings and graphic reconstructions of Vesuvian monuments are to be reported sketches, the relief and the proactive drawings of roofs, stairs, decorative interior details of some domus, performed by the architect-restorer Viollet-le-Duc during visits to Pompeian excavations carried out in 1864.

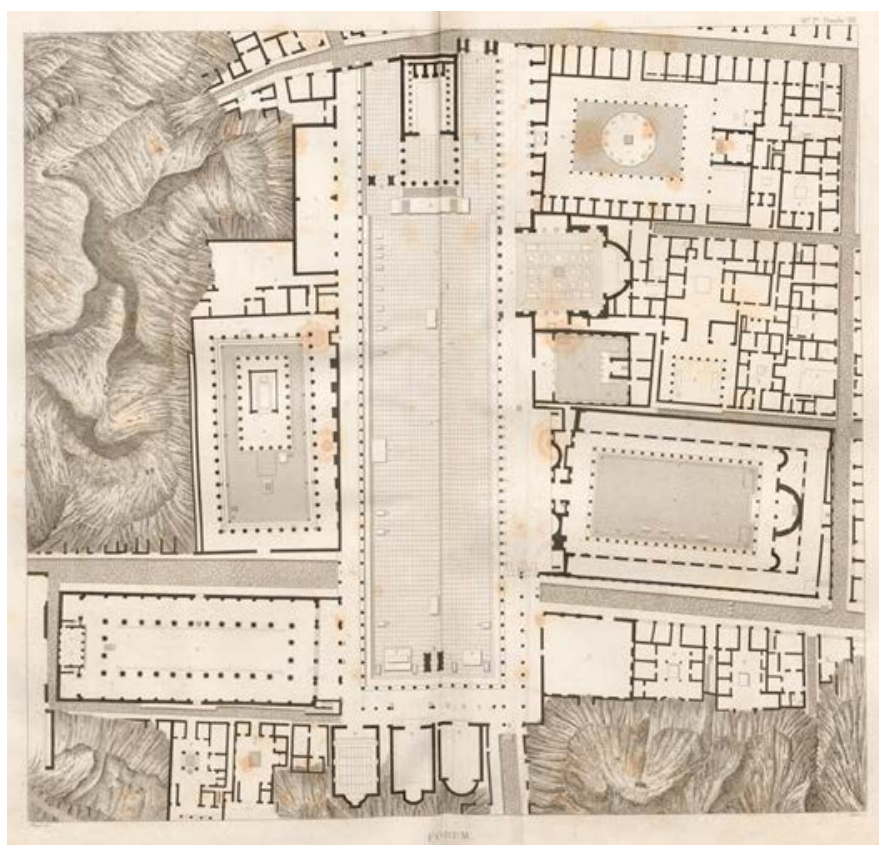

Fig. 4. Charles Francois Mazois, Les ruines de Pompéi, Paris, 1824, V. III Planche XIV 


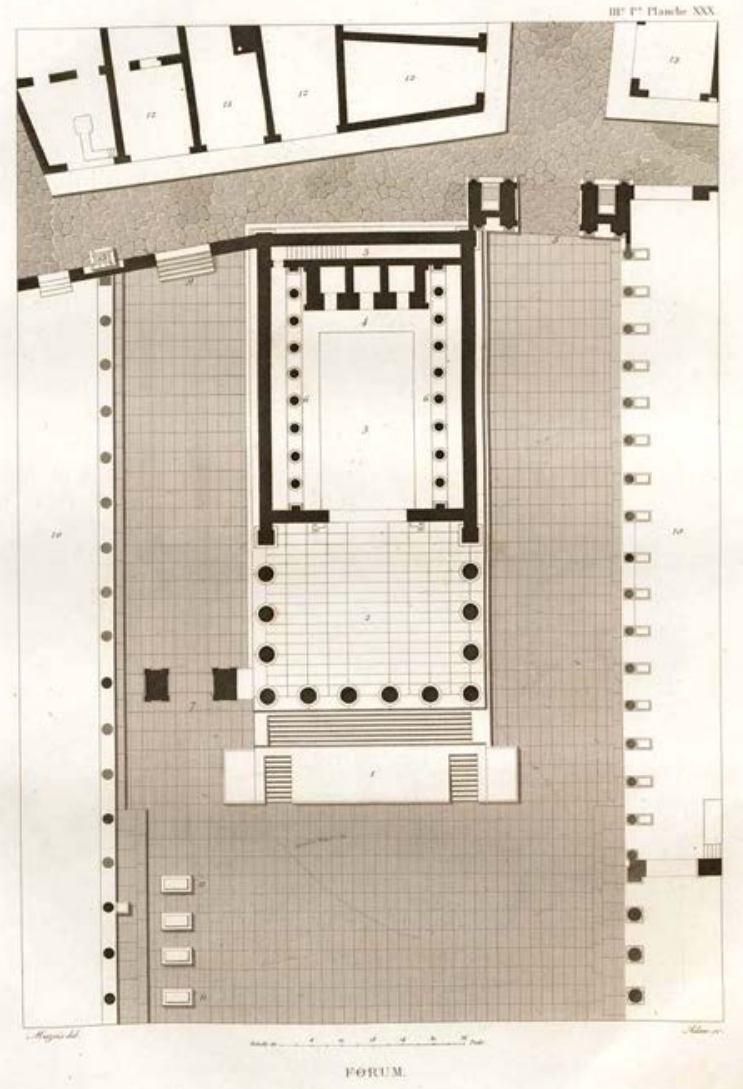

Fig. 5. Charles Francois Mazois, Les ruines de Pompéi, Paris, 1824, V. III Planche XXX

The survey of the wooden staircase of the domus of insula XII, regio VII, shows a frank and complete and constructive element discretization the detection method performed on the body of the object revealing the scientific research method. All the Pompeian stairs, the few that remain following the eruption of Vesuvius in $79 \mathrm{AD}$. C., can be studied by referring to the model of the famous architect and restorer. The drawing can also be compared to other ancient stairs in their distributive function of observable and measurable environment, investigating so on a logic and compositional element.



Fig. 6. Charles Francois Mazois, Les ruines de Pompéi, Paris, 1824, V. III Planche XXXI.

For the documentation of factories and urban assemblies Vesuvian reported gradually to light, it was also made use of a new means of investigation: the photography. Initially destined to tourists and to a public cultural and social chosen, used as a working tool by those who dedicated themselves to the study of antiquity, then constituted a valuable educational tool enabling an objective reading of the good.

One of the first scholars using this new method of recovery we are to remember the architects Alfred Nicolas Nornand and Francois Mazois and the archaeologist E. Trutat. Between the professionals photographers, however, they are known Leopoldo Alinari and his brothers Giacomo Brogi and Giorgio Sommer.

The Sommer is of considerable interest a photograph that takes environmental aspects of the Foro, of 10.2 centimeters by 14.2 centimeters perfect both in compositional achievement, both technically execution of shooting and printing. The hole was dug in 1812, is taken from the south side, while framed between two triumphal arches, stands the base of the temple of Giove.

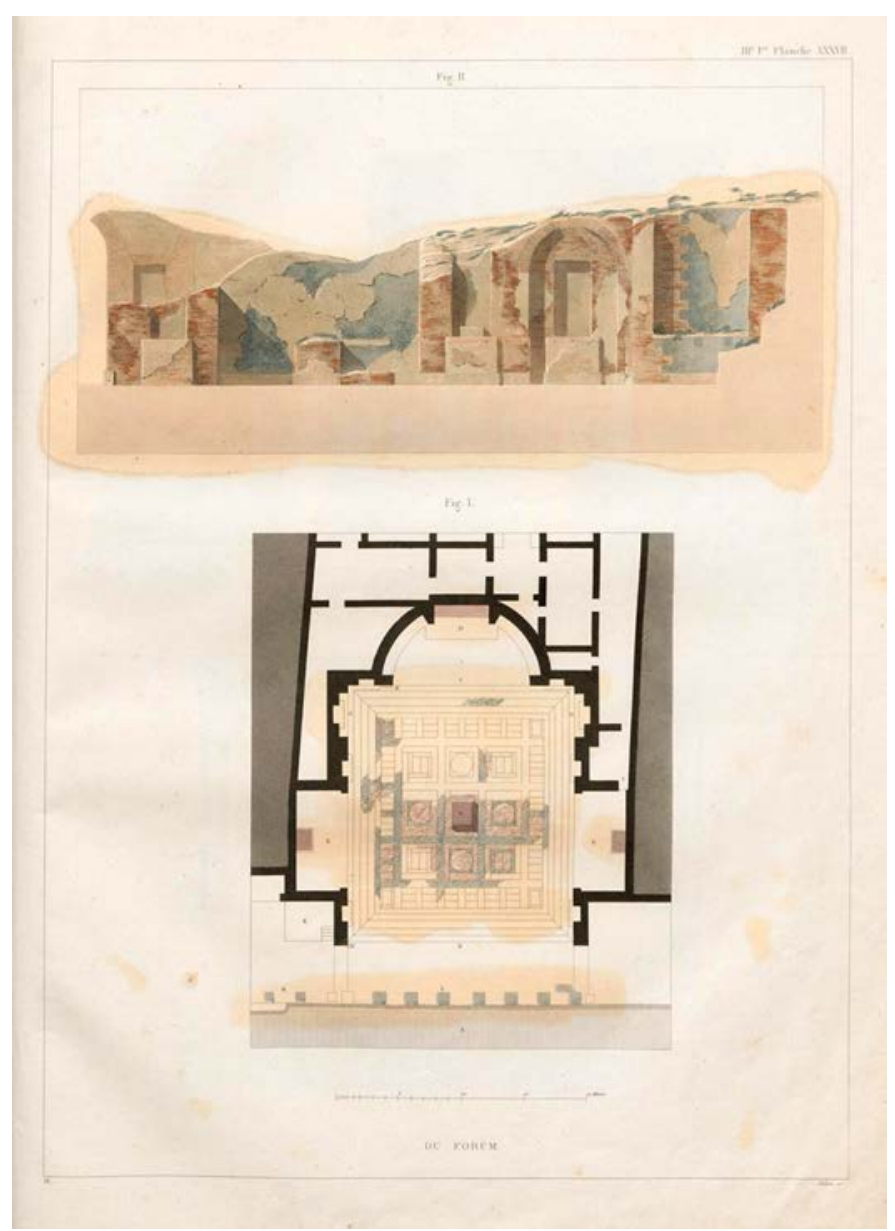

Fig. 7. Charles Francois Mazois, Les ruines de Pompéi, Paris, 1824, V. III Planche XXXVII.

\section{CONCLUSION}

The work of the impending archaeologist Giuseppe Fiorelli we owe the first archaeological excavation operations conducted with the application of a scientific method. 


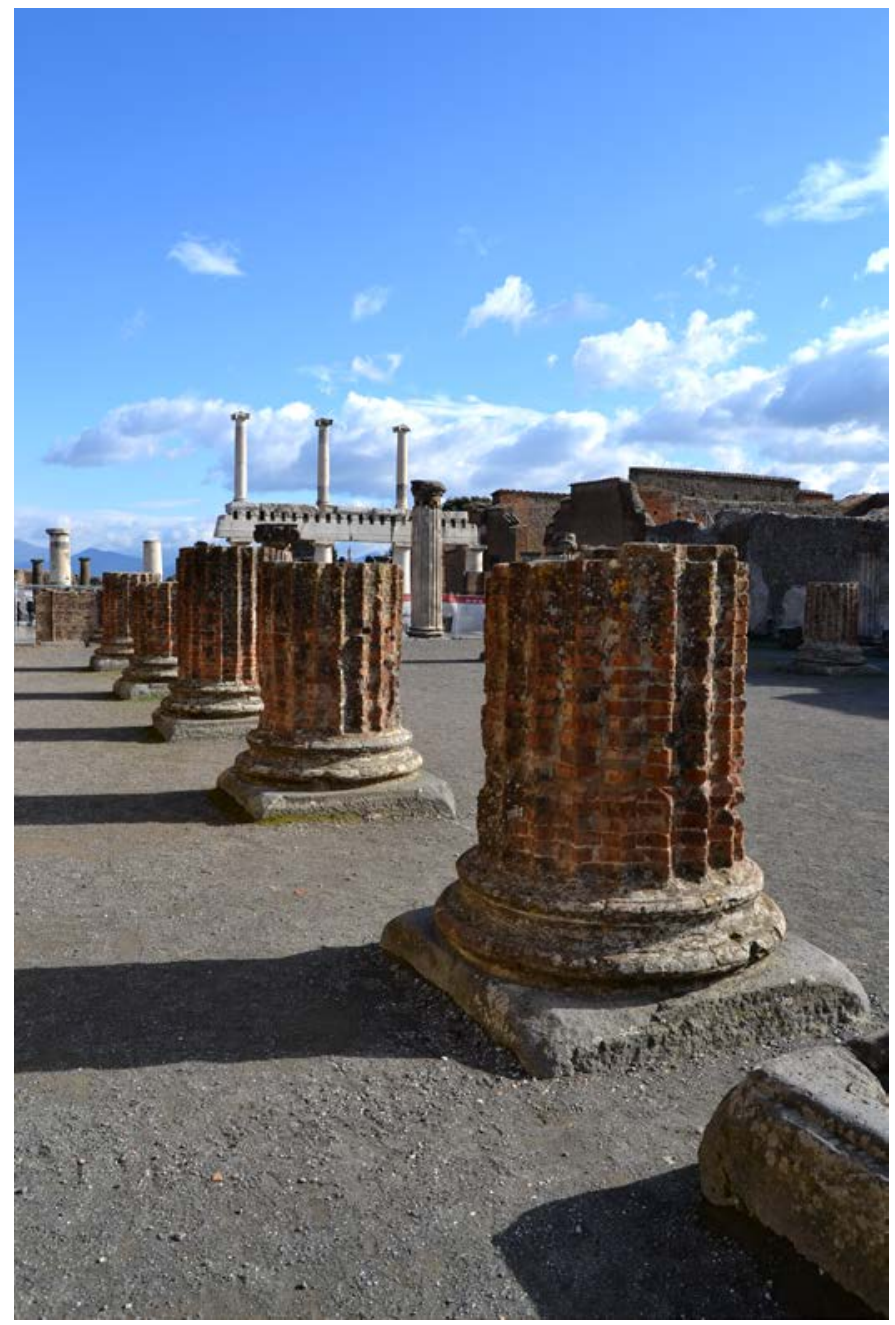

Fig. 8. Pompeii, the archaeological area, the Foro. (ph. Luigi Corniello 2016)

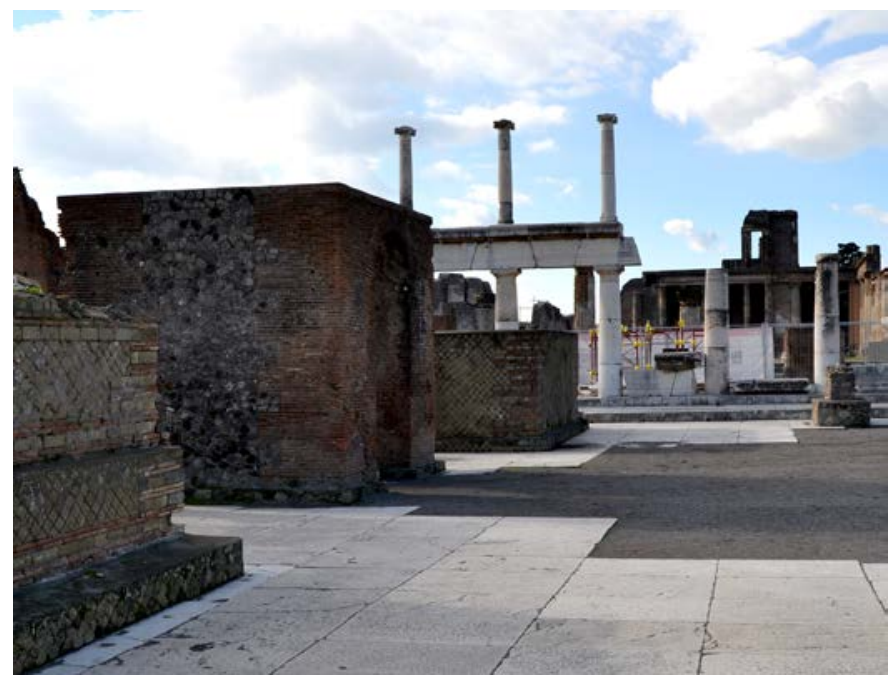

Fig. 9. Pompeii, the archaeological area, the Foro. (ph. Luigi Corniello 2016)

Starting from 1860 was it drafted a basic map of the city, still used today, which will become indispensable basis for the rigorous inventory of buildings.

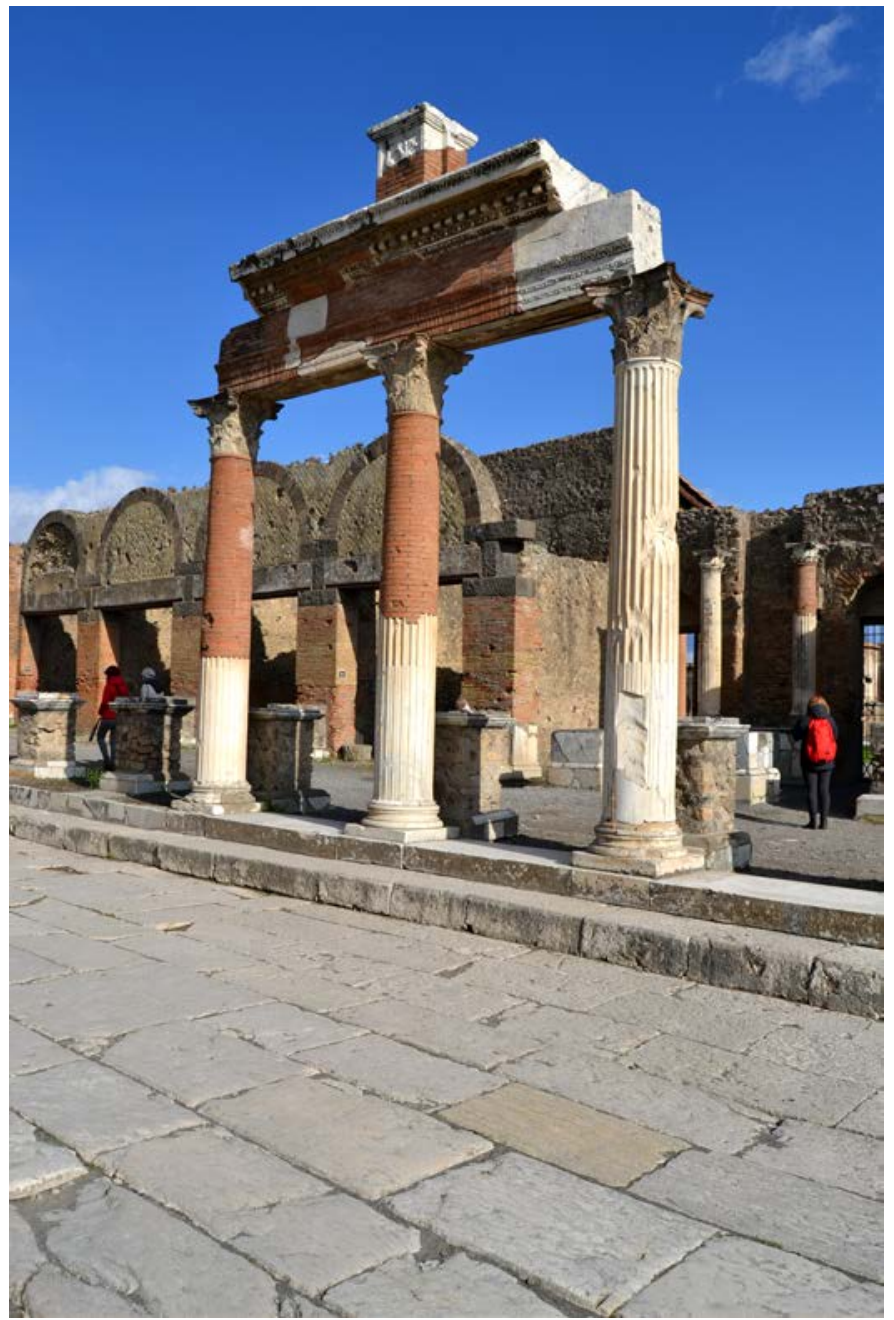

Fig. 10. Pompeii, the archaeological area, the Foro. (ph. Luigi Corniello 2016)

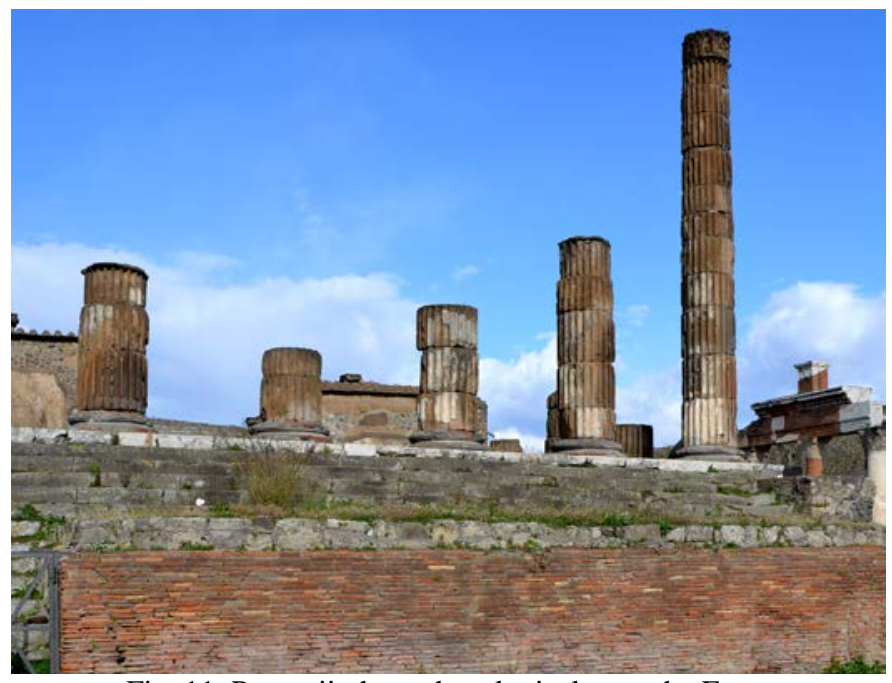

Fig. 11. Pompeii, the archaeological area, the Foro.

(ph. Luigi Corniello 2016)

Fiorelli devised a classification system of the urban fabric that the archaeological city was divided into nine districts (regiones), each of which consists of blocks (insulae), within which opened houses and shops. 




Fig. 12. Pompeii, the archaeological area, the domus.

(ph. Luigi Corniello 2016)

This allowed to uniquely identify the individual buildings within the urban fabric.

This urban form returned topographical organization of the ancient city in which the Pompeian house (domus) played a predominant role. The domus are complete in their distribution and also in the structural system of elevation while being for the most part free of the shell and of the upper floors destroyed by the event of '79 A.D. Their dates vary between the Samnite period, the pre-Roman and early imperial age with attendance of the first building expressions of Flavia age. To our reflections these offer so many moments of knowledge on their compositional values that surprise even for distribution solutions forerunners of those adopted in medieval and Renaissance factories.

\section{REFERENCES}

[1] L . Corniello, Il disegno multidimensionale della città di Ohrid in Macedonia. In: Disegno \& Città. A. Marotta, G. Novello, Roma: Gangemi Editore, 2015.

[2] L . Corniello, Knowledge in Apollonia. The medieval monastery and the territory. In: Heritage and Technology, Mind Knowledge Experience, C. Gambardella, Napoli: La scuola di Pitagora editrice, 2015.

[3] L . Corniello, Il Disegno delle architetture di culto a Tramonti. In: Gambardella C., Giordano P., Campania World Heritage Proprieties, Napoli: La scuola di Pitagora editrice, 2015.
[4] L . Corniello, The multidimensional approaches aimed at knowledge, conservation and regeneration of the Albanian territory. In: International Conference on Artificial Intelligence and Manufacturing Engineering (ICAIME'2014) \& International Conference on Architecture And Civil Engineering (ICAACE'14) \& 2014 International conference on Advanced Engineering Technologies (AET-2014). Dubai: URCAE, 2014.

[5] P. Giordano, L . Corniello, Atlante Grafico e Teorico Amalfitano. La conoscenza e la modificazione del paesaggio costiero. Napoli: La scuola di Pitagora editrice, 2014.

[6] L . Corniello, Le "1001" finestre tra passato e futuro / The "1001" windows between past and future. In: AA. VV., EGraFIA 2014: Revisiones del futuro, Previsiones del pasado. Rosario - Argentina, 1-3 ottobre 2014, Fisciano: Cues, 2014.

[7] L . Corniello, The representation of the coastal area of Naples. In: Gambardella C., Listokin D., Development and preservation in large cities: an international perspective (edition 2014). p. 207-209, Napoli: La scuola di Pitagora editrice, 2014.

[8] C. Gambardella, Atlante di Pompei, Napoli: La scuola di Pitagora editrice, 2012.

[9] P. Giordano, Il disegno dell'architettura costiera. Napoli: La scuola di Pitagora editrice, 2012.



Luigi Corniello, Architect, Doctor of Philosophy in "Environment and structures representation, protection and safety and land management" at the Department of Architecture and Industrial Design "Luigi Vanvitelli" of the Second University of Naples in international co direction by the Faculty of Architecture and Urban Planning of the Polytechnic University of Tirana (Albania).

He obtained, in February 2012, the Master in Management and Environmental Safety and participated in many training courses on the application of innovative technologies applied to architecture, landscape and cultural heritage.

He is a member Italian Union of Drawing and Italian Fulbright Association. He is a member of the International Scientific Committees. He is the author of about 60 scientific papers published in the volumes, in the conference proceedings and in the journals. He is the author, with Paolo Giordano, of the monograph Atlante Grafico e Teorico Amalfitano published in Naples, in 2014, by the publishing house La scuola di Pitagora. 